Journal of Zhejiang University-SCIENCE A (Applied Physics \& Engineering)

ISSN 1673-565X (Print); ISSN 1862-1775 (Online)

www.zju.edu.cn/jzus; www.springerlink.com

E-mail: jzus@zju.edu.cn

\title{
Review:
}

\section{Key problems faced in high-speed train operation*}

\author{
Xue-song JIN \\ (State Key Laboratory of Traction Power, Southwest Jiaotong University, Chengdu 610031, China) \\ E-mail: xsjin@home.swjtu.edu.cn \\ Received Nov. 12, 2014; Revision accepted Nov. 18, 2014; Crosschecked Nov. 19, 2014
}

\begin{abstract}
This paper discusses some key problems faced in high-speed train operation. These problems include: wheel tread concave wear causing the lateral oscillation of the train in operation, wheel roundness higher-order polygonal wear leading to fierce vertical vibration of wheel/rail and abnormal vibration noise of the coach interior of the train thus causing loosening and cracking of the train bogie parts, short pitch rail corrugation generation on the part of the track, fracture of cushion layer and road base fracture of the track, and increased noise inside and outside the train. At present, the mechanism of the occurrence and development of these phenomena is still not fully understood. This paper briefly reviews the related research on these problems in China and abroad, including many important recent papers and the articles published in this special issue. They make outstanding contributions to solving these problems, and include important work on train-track coupling large system theory, the relationship theory and technique of wheel/rail, and the vibration-noise reduction technology of the train.
\end{abstract}

Key words: High-speed railway, High-speed train, Wheel/rail wear, Train/Track coupling system dynamics, Wheel/Rail rolling contact theory, Vibration-noise reduction technology

doi: $10.1631 /$ jzus.A1400338

Document code: A

CLC number: U270

\section{Introduction}

At present, the total length of China's high-speed railway is close to $12000 \mathrm{~km}$, more than the sum of the rest of the world's high-speed railway coverage. Compared with other national high-speed railways, in addition to the first-class quality of train and track line, the train running speed is higher, the train marshalling is longer (16 coaches), the direct operating miles are longer (e.g., Harbin to Shanghai is $2421 \mathrm{~km}$, and Beijing to Guangzhou is $2289 \mathrm{~km}$ ), the track stiffness is larger, and the track lines have a higher proportion of bridges. As China's high-speed railway network is completed in length and breadth, with a

\footnotetext{
* Project supported by the National Basic Research Program (973) of China (No. 2011CB711103), the National High-Tech R\&D Program (863) of China (No. 2011AA11A103-2-2), and the National Natural Science Foundations of China (Nos. U1134202, U1434201, and 51475390)

(D) ORCID: Xue-song JIN, http://orcid.org/0000-0003-3033-758X

(c) Zhejiang University and Springer-Verlag Berlin Heidelberg 2014
}

particular emphasis in the western areas, the direct operating mileage of trains will increase further, and the proportions of bridges and tunnels in the track lines will be further increased. Trains operating on long direct lines will be on continuous high-speed running, across different geographical areas, and in different running environments. Different regional geological conditions could influence the track's behavior in various ways, including changes to the track support stiffness. Climate differences offer a different wheel/rail running environment, and a different abrasion state of wheel/rail. In addition, the wheel/rail adhesive coefficient difference is larger along a long track line. Large temperature differences can change greatly the operational features of the train and the track structure, even to the extent of affecting the vehicle system damping noise reduction effect. All this directly affects train dynamic behavior and operational quality, which makes it difficult to maintain long-term comfort, high stability and safety. To achieve such goals requires high reliability of the train and track structure. 
In high-speed operation, train wheels are excited by the irregularities of high-stiffness track (China's high-speed slab track), and the carriages and the bogies are strongly affected by high-speed airflow. The train's dynamic behavior becomes more complicated. These track irregularities mainly consist of the normal random irregularity of wheel/rail running surfaces, the periodic sleeper support of the rail, the rail welding joint, and periodic bridge pillar supports of the track. These periodic supports form hard points along with the track in the vertical and lateral directions. The strong effect of periodic hard points at operational speeds of $200-350 \mathrm{~km} / \mathrm{h}$ can be clearly seen in the measured acceleration and noise components in the frequency domain of the axle boxes, the bogie frames and the coaches. Under conditions of high-speed and high-stiffness track excitation, the wheel-rail excitation energy is large with a wide frequency band, the excitation frequencies are very high, and the track's energy absorption is poor. The wheel/rail interaction can effectively transfer their energy into the bogies, the coaches and rail infrastructure, and it is easy to cause vehicle and track system resonance. The vibration frequencies increase as the train speed increases, and since most of the structural parts of train and track are in a rigid-flexible coupling condition, this can produce high-frequency structural noise.

High-speed trains need urgently to solve the following problems: (1) The quick wheel tread concave wear caused when the train runs at high speed, and the lateral oscillating of the train at the frequencies of $7-10 \mathrm{~Hz}$. When the lateral oscillating amplitude is in excess of the prescribed threshold, the train monitoring system sends out an alarm signal and therefore the speed of the train is momentarily reduced (Cui et al., 2012); (2) The higher-order polygonal wear of wheel roundness leads to fierce vertical wheel/rail vibration, and therefore causes, at about $580 \mathrm{~Hz}$, fierce vibration and abnormal noise in the carriage ( $8 \mathrm{~dB}$ beyond normal) (Cui et al., 2013; Han et al., 2014b), and leads to fatigue cracking of key vehicle parts (Tian et al., 2013); (3) The noise level is a little high inside and outside the train carriages and the noise at the ends of the carriage interior exceed the standard (Zhang et al., 2014); (4) The vehicle/track system structure parameters (mainly referring to the structural modal parameters) does not achieve the best matching condition and the vehicle structure vibration transfer characteristics are not clear. The train's ability to resist outside turbulence (track disturbance due to irregularities and airflow turbulence due to the high-speed running) is weak, and in high-speed runtime resonance or short time jitter readily occurs; (5) The track has high stiffness, with a strong propensity to transmit vibration and a low damping capacity. The vehicle dynamic response can clearly reflect the characteristics of the track, such as sleeper pitch, rail welding points, and the pier spacing of the bridges. Fatigue damage of the mortar layer and roadbase of the track develops, which leads to track performance degradation (Chen and Sun, 2011); (6) The longitudinal dynamic behavior change of a long marshalling train and its influence on the lateral action of the train, and train safety assessment indicators, are all in need of further in-depth study. Relying only on existing theoretical analysis and experiment is insufficient for clear understanding and solution of the above problems. Railway engineers and researchers need to perfect a high-speed train-track coupling large system theory (Ling, 2012), in order to help understand these problems.

This paper discusses the progress of the research on these problems, mainly from the point of view of high-speed train track coupling large system theoretical modelling, the wheel/rail relationship and the damping noise reduction theory and technology, including the articles published in this special issue.

\section{Train-track coupling system dynamic model}

Root causes of the issues listed in Section 1 are very much related to many factors of the train and the track coupling condition. But which are the major, minor, and secondary factors? A complete theory of modeling of train-track large-scale coupling system and the numerical analysis helps to determine the answer.

Even far in the past there have been remarkable achievements in railway vehicle-track coupling dynamics modeling and its application. A series of researches have been carried out abroad. The theory of a dynamic simulation model started from the modelling 
of a single wheel in 1883 and this has continued from the multilayer track to the current mature singlevehicle/track coupling dynamics model (Ripke and Knothe, 1995; Oscarsson and Dahlberg, 1998). The model by Zhai et al. (1996) is the representative one in China. Its characteristic is that the ballasted track modelling considers five parameters nearly representing the dynamical behavior of the ballasted track. In a certain frequency range, it can characterize the effect of the ballast track characteristics on the vehicle-track coupling dynamics behavior. In these models, the vehicle modeling mainly depends on the multi-rigid-body system dynamics theory, where the components of the vehicle are treated to be rigid bodies, and they are connected with spring and damping elements. The dynamical behavior analysis of the vehicle is limited in the frequency range of 0 to $20 \mathrm{~Hz}$ (Knothe and Grassie, 1993). These models are mainly used for railway vehicle stability, comfort and safety assessment (Zhai et al., 2009). For a high-speed train, if the problems discussed in Section 1 are not included in the analysis, these models can also be used (Jin et al., 2013). However, in this case the interaction between the vehicles of the train is ignored.

In recent years, the high-speed railway around the world has been developing rapidly. The scale of the network increases, the operational speed continuously increases as does the pass-through mileage. Clearly, problems have emerged. High-speed operation causes qualitative and quantitative changes in the dynamical behavior of train/track, and using the existing theory can neither explain nor solve these problems. High-speed train/track coupling large system theory needs to be developed and perfected (Zhang et al., 2007). Its development is mainly along the following paths:

1. The modelling considers the vertical, horizontal, and longitudinal dynamic behavior coupling of high-speed train and track. Ling et al. (2014) in this special issue models the connections between adjacent vehicles of the train and the effect of the connections on the vertical and horizontal behavior. The analysis of vehicle stability, comfort and safety index has greatly improved, but we still lack understanding of the influence of the train longitudinal behavior, including acceleration, deceleration, vertical extrusion, collision, stretching, deformation and longitudinal wave, and structural characteristics, including train length, length of vehicles, and carriage longitudinal stiffness (Ling et al., 2014).

2. The modelling of the vehicle coupled with the track considers the effect of the rigid motion and the high-frequency deformation of the key structural parts, such as wheelsets (Zhong et al., 2013), bogie frame (Claus and Schiehlen, 2002) and carriages (Zhou et al., 2009) of the vehicles, rails (Xiao et al., 2008), and sleepers and slabs (Xiao, 2013) of the track. Here, in addition to the rail, the modeling of the sleeper and the wheelset mainly depends on the theory of beam model, and the modelling of the other main components is carried out by finite element methods, to determine their modals. Again according to the superposition principle, these models are put into the differential equations of the related parts of the vehicle and the track to find their solutions. Zhong et al. (2014) in this special issue considers the effect of wheels with 3-8 order polygonal wear on the wheel/rail rolling contact since the polygonal wear is much related to the wheelset $1-3$ order bending resonances occurring when the train operates at high speeds. Ling et al. (2014) considers the influence of rail and track slab flexible deformation. However, because of the difficulty of the problem and computing limitations, the present rigid-flexible coupling modeling cannot consider the whole system of vehicle-track, and is only local in scope. Thus, when at high speed, the local part models of the system, the overall modals, the local resonances, the system resonances as well as their relationship with wheel wear polygon, cannot be effectively identified and clearly understood.

3. The model of high-speed train considers mutual effect of the train's behavior and air flow. Factors for this problem include train aerodynamic drag, pressure changes inside the carriage, train induced flow, two running trains meeting in opposite directions, airflow effect, ground surface effect, tunneling effect, aerodynamic noise, and structural vibration, etc. (Li et al., 2013; Yu et al., 2013; Yang et al., 2014). These factors have a close relationship with the geometry and characteristic dimensions of the train, the embankment, the tunnel, the vehicle dynamic performance, and the assembly process. The study makes great progress in theory and practical application on these problems, such as that now 
high-speed trains running under $350 \mathrm{~km} / \mathrm{h}$ have better aerodynamic characteristics. Because of the complexity of these problems and the current limited calculation ability, in the analysis of the effect of high-speed air flow on the behavior of the train, the modelling does not fully consider the dynamic characteristics of the vehicle structure, namely, the effect of the rigid motion and high-frequency deformation of the structural parts on the high-speed air flow (Yu et al., 2011). So far, we do not know what causes the local high-frequency vibration of the floor-is it the wall and roof of the carriage, the wheel-rail excitation or air turbulence? The components of vibration and noise in the frequency range of 250 to $800 \mathrm{~Hz}$ are dominant. What are the root causes of the phenomena? These are not clear and open questions. In current studies on these problems, the train structure and its local complex structures are greatly simplified, such as fluid-structure interaction of pantograph and catenary (Lee et al., 2007), windshield fluid-structure coupling between the carriages (Song et al., 2008), and bogie fluid-structure coupling (Moon et al., 2014).

An overall view will be clearer, and problems solved with further improvement of modelling of high-speed train and track coupling system which can fully consider the structural rigid-flexible coupling and the fluid-structure coupling effect, combining this with the application of modern test technology.

\section{Interaction of wheel/rail}

Due to the long travelling distance and duration of high-speed trains running at high speed, structure materials of trains and track could change, and all kinds of hidden problems be gradually exposed, which could threaten safety. For China's high-speed railway, wheel/rail relationship problems mainly include: short pitch rail corrugation and wheel high-order polygonal wear that resulting in strong vibration and noise; rapid lateral concave wear on wheel tread and mismatching of low wear state of rail head that causing the lateral oscillation of the trains at high-speed, and therefore leading the train to slow down for a period. Fast wheel wear leads to shortening of the times between wheel repair intervals. Similarly, if the rail wear rate is much slower than that of the wheel, this will also lead to reductions in the intervals between essential repair of wheel and rail. Thus, wheel/rail material hardness matching remains to be further optimized.

Study of the relationship of wheel/rail includes the basic theory of wheel/rail in rolling contact or rolling contact mechanics and their application technologies. The application technologies of wheel/ rail are divided into research on the matching of the geometric surfaces and materials of wheel/rail, wheel/rail adhesion and its control, wear and rolling contact fatigue damage, as well as wheel/rail noise and derailment. The study involves many subjects, such as system dynamics, materials science, tribology, solid mechanics and calculation method, etc. (Jin and Shen, 2001; Zhai et al., 2010).

The theory of wheel/rail rolling contact is the basic means of guiding wheel/rail application technology research. This is mainly through the five classic wheel-rail creep theoretical models which reflect the wheel/rail rolling contact mechanics behavior, and the wheel/rail 3D elastic-plastic theory of rolling contact, developed more recently. The five classic wheel/rail force models are, the 1D wheel/rail rolling contact model (Carter, 1926), the 2D nonlinear wheel/rail creepage/force model (Vermeulen and Johnson, 1964), the 3D linear creep theory model of wheel/rail (Kalker, 1967) and the simplified theory model (Kalker, 1982), and the 3D wheel-rail creepage/force model with consideration of the effect of wheel/rail small spin (Shen et al., 1983). These models were built mainly based on the Hertz contact theory hypothesis, expressed in analytical form, and have been widely used in railway vehicle-track coupling dynamics modeling and computational simulation. Their advantage is that they have fast speed in the wheel/rail force calculation. But these models do not consider the effect of train wheel rolling, wheel/rail transient behavior, wheel/rail environment boundary factors and changes in material properties. Thus, using them cannot effectively solve some problems in the service condition of wheel/rail, such as wheel high-order polygonal wear, rail short pitch corrugation, strong vibration noise, and wheel/rail rolling contact fatigue. It is urgent and necessary to develop a more complex wheel/rail rolling contact theory model to clearly understand and effectively solve them. This theoretical model should be the wheel/rail 3D elastic-plastic rolling contact theory model and the corresponding numerical method. 
In the 1970s, Kalker (1990), according to the variational principle, used variational inequality to express the problem of elastic bodies in rolling contact with friction, and its corresponding numerical program, called "CONTACT", has been widely used in wheel/rail rolling contact behavior analysis. Using the theory it is possible to get information about the behavior of wheel/rail, whereas using the five classic models discussed above cannot (Jin and Shen, 2008). The information includes the wheel/rail contact spot real shape, the stick-slip area distribution, the size and distribution of the tangential force, the normal force and the spin moment, the distribution of the friction work, and the wheel/rail stress distribution in the wheel/rail bodies. Compared to the above classic creep force models, however, its calculation speed is slow. The establishment of the theoretical model "CONTACT" does not depend on the assumptions of the Hertz contact theory, and thus it is called the non-Hertz rolling contact theory. Its numerical implementation process is based on the theory of elastic half space, and the numerical results of wheel/rail forces gained by using it are a little greater than the results of the finite element model. This is because the wheel/rail is regarded as two elastic half space objects in the "CONTACT" model, which exaggerates the actual wheel/rail contact rigidity. This model cannot consider the rolling speed change effect and wheel/rail transient behavior. Furthermore, it ignores the effects of the structural deformation of the wheel/rail and the wheel/rail surface state (roughness, the third medium), and the environmental conditions (temperature, humidity, and air flow). Jin and Zhang (2001) and Zhang S.R. et al. (2013) used the finite element method to further promote the "CONTACT" model, which can take into account the influence of the geometry boundary condition outside wheel/rail contact point on the rolling contact behavior.

Starting in the 1980s, the finite element method has been applied to the analysis of wheel/rail rolling contact behavior. Damme et al. (2003) introduced stick-slip contact control conditions, and utilized the decomposition method of deformation gradient of liquid layout and the arbitrary Lagrange-Euler method to analyze the 3D elastic bodies in rolling contact, in which fine grid adaptive technology was used. This numerical method is only suitable for solving the steady rolling contact problem of 3D elastic bodies. In the analysis, the rolling speed was low $(10 \mathrm{~km} / \mathrm{h})$, non-slip condition was considered, and the contact surfaces were assumed to be smooth (Nackenhorst, 1993).

Now, high-speed trains operate at speeds up to $350 \mathrm{~km} / \mathrm{h}$, and the test speed reaches $500 \mathrm{~km} / \mathrm{h}$. Wheel/rail in service repeatedly encounters the acceleration deceleration, and the excitation by wheel/rail contact surface irregularity (wheel wear polygon, rail corrugation, rail welding joint, rail scratch, wheel flat, turnout and various irregularities by rail grinding). The wheel/rail rolling contact process is a transient elastic-plastic deformation process in rolling contact. Using the rolling contact theory model discussed above still cannot explain the wheel/rail unsteady rolling phenomenon and the mechanism of some problems. Zhao and Li (2011), by using the commercial software ANSYS/LS-DYNA, developed the model of 3D elastic-plastic wheel/rail in rolling contact to analyze the dynamical behavior of wheel and rail when the wheel is rolling over the rail with the squat on the rail top. In their model, the actual geometrical sizes of the wheel, the rail and the vehicle's unsprung mass, and the parameters of the track characteristics were considered. The wheel/rail rolling speed in the analysis can be simulated to $40-140 \mathrm{~km} / \mathrm{h}$. In this special issue, Zhao et al. (2014) further promotes the development of the calculation model of the 3D elastic-plastic wheel-rail in rolling contact. This model can be used to accurately and reliably analyze the high frequency vibration of the wheel/rail system, and unsteady elastic-plastic rolling contact behavior in the variety of irregular excitation cases (rail welding joint, geometrical and material defects, rail corrugation, wheel/rail contact surface scratches and wear, triangle pit, etc.). Situations of the wheel rolling over the rail at high speed with unsteady rolling-slip, wheel/rail contact spot shape, stick-slip area distribution, wheel/rail creep force, and elasticplastic stress and strain in the wheel/rail can be also calculated. In the calculation the simulated rolling speed reaches $500 \mathrm{~km} / \mathrm{h}$ (Zhao et al., 2014). However, the model calculation speed is very slow, and cannot meet the requirements of high-speed and efficient numerical simulation. This model does not consider the effects of the environmental temperature, the contact surface asperity, the "three media" between wheel and rail, and the material inclusions in the wheel/rail (Wu et al., 2014). 
Study on the wheel/rail relationship also includes the wheel/rail matching design theory and technology (Cui et al., 2011), the adhesion theory and adhesion control technology (Chen et al., 2005), the rolling contact fatigue (Wen et al., 2005), the derailment mechanism and control (Xiao et al., 2012), as well as the wheel/rail noise problem (Han et al., 2014a).

At present, wheel/rail studies face many unresolved issues. The best matching design of wheel/rail materials tries to achieve the goal that the wear and fatigue crack growth rates of the wheel/rail materials in service achieve synchronous progress, and then expect that the performance of the selected wheel/rail materials can satisfy the best and longest service cycle through the wheel/rail natural wear eliminating the rolling contact fatigue crack on the surface of the wheel/rail contact, thus reducing wheel/rail maintenance cost. At a running speed under $350 \mathrm{~km} / \mathrm{h}$, the wheel/rail noise contribution is still over $50 \%$ of the total noise of the whole train/track system. For running safety, there are currently no effective measures to solve the problem of wheel/rail noise from their source. Wheel wear rate increases quickly due to the high operation speed, the high-stiffness track, the wide wheel/rail impact frequency, and large vibration amplitude. Furthermore, the high wheel wear rate causes the conicity and roundness of the wheel to change quickly, and the train cannot keep a good ride quality for a long period. Therefore, the wheels frequently need to be re-profiled and the operating costs rise.

\section{Vibration and noise}

As speeds increase, the vibration and noise problem has become increasingly prominent. As can be seen from a direct personal sensory comfort index, vibration and noise have become the key factors influencing high-speed train business competition. In general, research on noise and its control has three elements, i.e., source, propagation path, and sound receiver. Controlling the former two is the active measure. The noise sources of high-speed train can be divided into wheel/rail noise, train aerodynamic noise, pantograph/catenary noise, and auxiliary equipment noise. Their propagation paths include air sound transmission and structure sound transmission (Eade and Hardy, 1977).
In practice, the vibration and noise of a high-speed train are related to the source excitation energy and the complex propagation path. For example, some typical vibration and noise problems are: (1) wheel/rail excitation at the passing frequency of the sleepers (e.g., $110 \mathrm{~Hz}$ at $250 \mathrm{~km} / \mathrm{h}$ ) can pass to the carriage through the bogie structure, and inspire the local structure modes of the vehicle and the special acoustic modes of interior cavity. In such a situation sound-solid coupling forms in the carriage, and the noise level of the passenger compartment end near the window is $8 \mathrm{~dB}(\mathrm{~A})$ higher than that of the carriage corridor at the same cross section of the carriage (Zhang et al., 2014a); (2) Due to the carriage special structure design and layout of the built-in dining car, the dining car uses a large number of rigid connection structures and does not benefit from the damping measures at the connections, which leads to the increase of the structural system vibration energy under the external excitation (wheel/rail and air-flow). At the same time, the carriage interior decoration uses materials with a low absorption coefficient, which generates the large reverberation noise inside the carriage. Therefore, the dining car interior noise is significantly higher than other carriages, particularly when excited by the wheel wear polygon (Zhang et al., 2013b); (3) The sound insulation and sealing of the carriage structure is not sufficient. At the passenger compartment end above the bogie, due to the toilet layout, there are many pipes installed on the bodywork chassis. The aluminum profile used in the bodywork chassis has many holes where leaking sound directly generates, which leads to the area noise of $3 \mathrm{~dB}(\mathrm{~A})$ higher than the other end of the carriage where an electrical cabinet is installed; (4) High-frequency sound transmission is through the structures under the carriage. The existing wheel higher-order wear polygon excites the high-frequency vibration response of the wheel/rail system and the resonance of the auxiliary equipment at their natural frequency close to the passing frequency of the wear polygon. The resonance easily passes to the carriage through the suspension systems and the rod pieces under the carriage. Hence, the measured results of the interior vibration and noise show a great peak at the passing frequency of the wheel wear polygon; (5) The car-body surface aerodynamic noise sources mainly include the train head area, the pantograph area and the area between carriages and the bogie area. In these areas, due to the strong aerodynamic effect, the 
corresponding pneumatic noise and vibration response of the carriage structure are quite high; (6) Some of the latest site test results also show that the air conditioning duct and carriage grid structures can sometimes increase active equipment vibration and then the noise level inside the carriage increases dramatically.

Färm (2000) conducted the testing analysis through equipment transposition and found that the excitation by different stiffness track and different sleeper passing frequency made an $11 \mathrm{~dB}(\mathrm{~A})$ difference in the total noise level, and that $\mathrm{SJ} 50$ rail is more likely to provoke vehicle vibration, compared to UIC60 rail. By changing the sleeper spacing, track stiffness and wheelbase vehicle vibration can effectively be eliminated at the sleeper passing frequency. Eade and Hardy (1977), by changing the primary and secondary suspension parameters, concluded that, compared with the second suspension, installing damper at the primary suspension can better improve the interior vibration and noise of the carriage. Through the test and analysis of aerodynamic noise characteristics at the carriage connection and bogie of the French TGV high-speed train, it was concluded that the former is mainly the narrow frequency domain noise in low frequency $(500 \mathrm{~Hz})$, and the latter is mainly the high-frequency noise in $500-1000 \mathrm{~Hz}$ range (Poisson et al., 2002). The high-speed trains of Japanese Shinkansen adopted streamlined head cars and smooth surfaces in vitro, such that smooth connections between the carriages and other uneven places (side window and side sliding door, etc.), replaced the diamond pantograph for the single-arm pantograph and used pantograph air guide sleeve, and in the area of bogie with bottom cover and apron. These measures can obtain an obvious noise reduction (Akihiko, 2003). Further research on the sound source identification technology and application showed that the main noise sources of high-speed trains are, the bogie area, the pantograph/catenary area, the carriage connection area, and train head. The interior noise of $200-800 \mathrm{~Hz}$ is dominant (Mellet et al., 2006; Poisson et al., 2008). Research on the mechanism of wheel/rail noise and noise reduction technology is also actively developing (Jones and Thompson, 2000; Thompson and Gautier, 2006).

In this special issue, He et al. (2014) discusses the experiment and analysis of external noise produced by a Chinese high-speed train traveling at different speeds. The experimental results and their corresponding analysis are very useful for the control and reduction of exterior noise produced by highspeed trains (He et al., 2014). Zhang et al. (2014b) investigates the effect of wheel wear polygon of a high-speed train on the interior noise of the carriage. The results have a positive role in control measure research of the outside and interior noise of high-speed trains. However, train operation safety is the basic and first priority. Therefore, the noise reduction measures taken in wheel/rail systems are currently very limited at the sound source.

Other research on the vibration and noise includes the evaluation methods of interior noise (Hardy, 2000; Zhang et al., 2013a), the sound quality evaluation of the interior carriage (Letourneaux and Guerrand, 2000; Parizet et al., 2002), etc. There are many unsolved key issues, including in time domain vibration noise mechanism research, the highfrequency sound transmission mechanism of the bogie structure, lightweight carriage and reliable acoustic design, sound-solid coupling, vehicle sound quality mechanism, and active noise control methods.

\section{Further work}

This paper has described some of the urgent problems needing a solution and the research progress of them. These problems are still open and need of extensive investigations:

1. For current and future operation, all-round tracking tests and statistical analysis should be carried out, to obtain the relationship between the high-speed wheel/rail service state and the vehicle dynamic performance, and the main factors that influencing the wear and rolling contact fatigue of wheel/rail on lines with different operational speed levels in different geographical areas.

2. Train-track coupling system dynamics theory should fully consider, in the high speed running state, the influence of structure rigid-flexible coupling and fluid-structure interaction on train-track behavior.

3. The design method for wheel/rail geometric profile matching needs to be improved. Research on new wheel/rail modification technology should be conducted.

4. Comprehensive material testing for wheel/rail use should be carried out, with long-term research on wheel/rail new materials and their preparation. 
5. Wheel/rail contact surface processing technology needs to be improved with corresponding field test research carried out at the same time.

6. With consideration of the vehicle-track coupling system environment, the 3D elastic-plastic rolling contact model of wheel-rail should be improved. There should be focus on computational efficiency, the wheel/rail material defect effect, the contact surface state, the wheel/rail environmental impact, and the wheel/rail spin effect.

7. Broad-based and in-depth theory, technology and measures of vibration attenuation and noise reduction for high-speed train and track coupling systems should be developed.

\section{References}

Akihiko, T., 2003. The noise reduction measures for Shinkansen 700 series train-sets. Foreign Rolling Stock, 40(6):17-19.

Carter, F., 1926. On the action of a locomotive driving wheel. Proceedings of the Royal Society of London, Series A, 112:151-157.

Chen, H., Ishida, M., Nakahara, T., 2005. Analysis of adhesion under wet conditions for three-dimensional contact considering surface roughness. Wear, 258(7-8):1209-1216. [doi:10.1016/j.wear.2004.03.031]

Chen, S.Y., Sun, H.L., 2011. Experimental analysis of long-term stability of soaking subgrade for high speed railway. Journal of Railway Engineering Society, 12: 40-44 (in Chinese).

Claus, H., Schiehlen, W., 2002. Symbolic-numeric analysis of flexible multibody systems. Mechanics of Structures and Machines, 30(1):1-30. [doi:10.1081/SME-120001476]

Cui, D.B., Li, L., Jin, X.S., et al., 2011. Optimal design of wheel profiles based on weighed wheel rail gap. Wear, 271(1-2):218-226. [doi:10.1016/j.wear.2010.10.005]

Cui, D.B., Huang, Z.W., Jin, X.S., et al., 2012. A new wheel profile design method for high-speed vehicle. Proceedings of the 1st International Workshop on High-speed and Intercity Railways, 1, Lecture Notes in Electrical Engineering, 147:225-241. [doi:10.1007/978-3-642-27960-7 20]

Cui, D.B., Lin, L., Song, C.Y., et al., 2013. Out of round high-speed wheel and its influence on wheel/rail behavior. Journal of Mechanical Engineering, 49:8-16 (in Chinese).

Damme, S., Nackenhorst, U., Wetzel, A., et al., 2003. On the numerical analysis of the wheel-rail system in rolling contact. System Dynamics and Long-term Behaviour of Railway Vehicles, Track and Subgrade, Springer, p.155-174.

Eade, P.W., Hardy, A.E.J., 1977. Railway vehicle internal noise. Journal of Sound and Vibration, 51(3):403-415.

Färm, J., 2000. Interior structure-borne sound caused by the sleeper-passing frequency. Journal of Sound and Vibration, 231(3):831-837.
Han, J., Wen, Z.F., Wang, R.Q., et al., 2014a. Experimental study on vibration and sound radiation reduction of the web-mounted noise shielding and vibration damping wheel. Noise Control Engineering Journal, 62(3):110122. [doi:10.3397/1/376211]

Han, G.X., Zhang, J., Xiao, X.B., et al., 2014b. Study on high-speed train abnormal interior vibration and noise related to wheel roughness. Journal of Mechanical Engineering, in press (in Chinese).

Hardy, A.E.J., 2000. Measurement and assessment of noise within passenger trains. Journal of Sound and Vibration, 231(3):819-829. [doi:10.1006/jsvi.1999.2565]

He, B., Xiao, X.B., Zhou, Q., et al., 2014. Investigation into external noise of a high-speed train at different speeds. Journal of Zhejiang University-SCIENCE A (Applied Physics \& Engineering), 15(12):1019-1033. [doi:10. 1631/jzus.A1400307]

Jin, X.S., Zhang, J.Y., 2001. A complementary principle of elastic bodies of arbitrary geometry in rolling contact. Computers \& Structures, 79(29-30):2635-2644. [doi:10. 1016/S0045-7949(01)00087-6]

Jin, X.S., Shen, Z.Y., 2001. Development of rolling contact mechanics and its application in research on wheel/rail performances. Advances in Mechanics, 31(1):33-46.

Jin, X.S., Shen, Z.Y., 2008. Wheel/Rail Creep Theory and Its Experiments. Southwest Jiaotong University Press, Chengdu, China (in Chinese).

Jin, X.S., Xiao, X.B., Ling, L., et al., 2013. Study on safety boundary for high-speed train running in severe environments. International Journal of Rail Transportation, 1(1-2):87-108. [doi:10.1080/23248378.2013.790138]

Jones, C.J.C., Thompson, D.J., 2000. Rolling noise generated by railway wheels with visco-elastic layers. Journal of Sound and Vibration, 231(3):779-790. [doi:10.1006/ jsvi.1999.2562]

Kalker, J.J., 1967. On the Rolling Contact of Two Elastic Bodies in the Presence of Dry Friction. PhD Thesis, Delft University, The Netherlands.

Kalker, J.J., 1982. A fast algorithm for the simplified theory of rolling contact. Vehicle System Dynamics, 11(1):1-13. [doi:10.1080/00423118208968684]

Kalker, J.J., 1990. Three-dimensional Elastic Bodies in Rolling Contact. Kluwer Academic Publishers, Dordrecht, The Netherlands.

Knothe, K., Grassie, S.L., 1993. Modeling of railway track and vehicle/track interaction at high frequencies. Vehicle System Dynamics, 22(3-4):209-262.

Lee, Y.B., Rho, J., Kwak, M.H., et al., 2007. Aerodynamic characteristics of high speed train pantograph with the optimized panhead shape. Proceedings of the 7th IASME/WSEAS International Conference on Fluid Mechanics and Aerodynamics, p.84-88.

Letourneaux, F., Guerrand, S., 2000. Assessment of the acoustical comfort in high-speed trains at the SNCF: integration of subjective parameters. Journal of Sound and Vibration, 231(3):839-846. [doi:10.1006/jsvi.1999.2567]

Li, T., Zhang, J.Y., Zhang, W.H., 2013. A numerical approach to the interaction between airflow and a high-speed train subjected to crosswind. Journal of Zhejiang University- 
SCIENCE A (Applied Physics \& Engineering), 14(7): 482-493. [doi:10.1631/jzus.A1300035]

Ling, L., 2012. Study on the Dynamic Behaviour of High-speed Train/Track Coupling System Composed of Multiple Vehicles. Southwest Jiaotong University, MS Thesis (in Chinese).

Ling, L., Xiao, X.B., Xiong, J.Y., et al., 2014. A 3D model for coupling dynamics analysis of high-speed train/track system. Journal of Zhejiang University-SCIENCE A (Applied Physics \& Engineering), 15(12):964-983. [doi:10.1631/jzus.A1400192]

Mellet, C., Letourneau, F., Poissonb, F., et al., 2006. High speed train noise emission: latest investigation of the aerodynamic/rolling noise contribution. Journal of Sound and Vibration, 293(3-5):535-546. [doi:10.1016/j.jsv. 2005.08.069]

Moon, J.S., Kim, S.W., Kwon, H.B., 2014. A study on the aerodynamic drag reduction of high-speed train using bogie side fairing. Journal of Computational Fluids Engineering, 19(1):41-46. [doi:10.6112/kscfe.2014.19.1. 041]

Nackenhorst, U., 1993. On the finite element analysis of steady state rolling contact. Contact Mechanics-Computational Techniques. Computational Mechanics Publication, Southampton, Boston, p.53.

Oscarsson, J., Dahlberg, T., 1998. Dynamic train/track/ballast interaction - computer model and full-scale experiments. Vehicle System Dynamics, 29(S1):73-84. [doi:10. 1080/00423119808969553]

Parizet, E., Hamzaoui, N., Jacquemoud, J., 2002. Noise assessment in a high-speed train. Applied Acoustics, 63(10): 1109-1124. [doi:10.1016/S0003-682X(02)00017-8]

Poisson, F., Letourneaux, F., Loizeau, T., et al., 2002. Inside noise of high speed train coaches. Forum Acusticum Sevilla, High Speed Trains, NOI-03-005-IP.

Poisson, F., Gautier, P.E., Letourneaux, F., 2008. Noise sources for high speed trains: a review of results in the TGV Case. Noise and Vibration Mitigation for Rail Transportation Systems, 99:71-77. [doi:10.1007/978-3-540-74893-9_10]

Ripke, B., Knothe, K., 1995. Simulation of high frequency vehicle-track interactions. Vehicle System Dynamics, 24(S1):72-85. [doi:10.1080/00423119508969616]

Shen, Z.Y., Hedric, K.J., Elkins, J., 1983. A comparison of alternative creep force models for rail vehicle dynamic analysis. Vehicle System Dynamics, 12(1-3):79-83. [doi:10.1080/00423118308968725]

Song, H., Park, J.H., Song, S., 2008. Numerical analysis on flow characteristics around a cavity with flaps. 32(9): 645-651 (in Korean). [doi:10.3795/KSME-B]

Thompson, D.J., Gautier, P.E., 2006. Review of research into wheel/rail rolling noise reduction. Proceedings of the Institution of Mechanical Engineers, Part F: Journal of Rail and Rapid Transit, 220(4):385-408. [doi:10.1243/ 0954409JRRT79]

Tian, J.Y., Yang, Y., Zhang, S., et al., 2013. Gearbox fault diagnosis technology of high-speed trains. Mechanical Engineer, 6:77-78 (in Chinese).

Vermeulen, J.K., Johnson, K.L., 1964. Contact of nonspherical bodies transmitting tangential forces. Journal of Applied Mechanics, 31(2):338-340. [doi:10.1115/1. 3629610]
Wen, Z.F., Jin, X.S., Jiang, Y.Y., 2005. Elastic-plastic finite element analysis of non-steady state wheel-rail rolling contact. Tribology, ASME, 127(4):713-721. [doi:10. 1115/1.2033898]

Wu, B., Wen, Z.F., Wang, H.Y., et al., 2014. Numerical analysis on wheel/rail adhesion under mixed contamination of oil and water with surface roughness. Wear, 314(1-2): 140-147. [doi:10.1016/j.wear.2013.11.041]

Xiao, X.B., 2013. Study on High-speed Train Derailment Mechanism in Severe Environment. PhD Thesis, Southwest Jiaotong University, Chengdu, China (in Chinese).

Xiao, X.B., Jin, X.S., Deng, Y.Q., et al., 2008. Effect of curved track support failure on vehicle derailment. Vehicle System Dynamics, 46(11):1029-1059. [doi:10.1080/ 00423110701689602]

Xiao, X.B., Ling, L., Jin, X.S., 2012. A study of the derailment mechanism of a high-speed train due to an earthquake. Vehicle System Dynamics, 50(3):449-470. [doi:10.1080/ 00423114.2011.597508]

Yang, Z.P., Liu, W.Z., Zhao, G.L., et al., 2014. Research on key mechanics problems in high-speed trains. Advances in Mechanics, in press (in Chinese).

Yu, M.G., Zhang, J.Y., Zhang, W.H., 2011. Wind-induced security of high-speed trains on the ground. Journal of Southwest Jiaotong University, 46(6):989-995 (in Chinese).

Yu, M.G., Zhang, J.Y., Zhang, W.H., 2013. Multi-objective optimization design method of the high-speed train head. Journal of Zhejiang University-SCIENCE A (Applied Physics \& Engineering), 14(9):631-641. [doi:10.1631/ jzus.A1300109]

Zhai, W.M., Cai, C.B., Guo, S.Z., 1996. Coupling model of vertical and lateral vehicle/track interactions. Vehicle System Dynamics, 26(1):61-79. [doi:10.1080/ 00423119608969302]

Zhai, W.M., Wang, K.Y., Cai, C.B., 2009. Fundamentals of vehicle-track coupled dynamics. Vehicle System Dynamics, 47(11):1349-1376. [doi:10.1080/00423110802621 561]

Zhai, W.M., Jin, X.S., Zhao, Y.X., 2010. Some typical mechanics problems in high-speed railway engineering. Advances in Mechanics, 40(4):358-374 (in Chinese).

Zhang, S.G., Zhang, W.H., Jin, X.S., 2007. Dynamics of high speed wheel/rail system and its modeling. Chinese Science Bulletin, 52:1566-1575.

Zhang, S.R., Li, X., Wen, Z.F., et al., 2013. Theory and numerical method of elastic bodies in rolling contact with curve contact area. Engineering Mechanics, 30(2):30-37 (in Chinese)

Zhang, J., Xiao, X.B., Zhang, Y.M., 2013a. Noise evaluation in the tourist cabin of high-speed train by using aircraft noise criterion. Journal of Mechanical Engineering, 49(16): 33-38 (in Chinese). [doi:10.3901/JME.2013.16.033]

Zhang, J., Xiao, X.B., Han, G.X., et al., 2013b. Study on abnormal interior noise of high-speed trains. Proceedings of the 11th International Workshop on Railway Noise, Uddevalla, Sweden, p.759-766.

Zhang, J., Xiao, X.B., Han, J., et al., 2014a. Characteristics of abnormal noise at the ends of the coach and acoustic 
modal analysis of high-speed train. Chinese Journal of Mechanical Engineering, 50(12):97-103 (in Chinese).

Zhang, J., Han, G.X., Xiao, X.B., et al., 2014b. Influence of wheel polygonal wear on interior noise of high-speed trains. Journal of Zhejiang University-SCIENCE A (Applied Physics \& Engineering), 15(12):1002-1018. [doi:10.1631/jzus.A1400233]

Zhao, X., Li, Z., 2011. The solution of frictional wheel-rail rolling contact with a 3-D transient finite element model: validation and error analysis. Wear, 271:444-452.

Zhao, X., Wen, Z.F., Wang, H.Y., et al., 2014. Modeling of high-speed wheel-rail rolling contact on a corrugated rail and corrugation development. Journal of Zhejiang University-SCIENCE A (Applied Physics \& Engineering), 15(12):946-963. [doi:10.1631/jzus.A1400191]

Zhong, S.Q., Xiao, X.B., Wen, Z.F., et al., 2013. The effect of first-order bending resonance of wheelset at high speed on wheel-rail contact behavior. Advances of Mechanical Engineering, 2013:1-19.

Zhong, S.Q., Xiong, J.Y., Xiao, X.B., et al., 2014. Effect of the first two wheelset bending modes on wheel-rail contact behavior. Journal of Zhejiang University-SCIENCE A (Applied Physics \& Engineering), 15(12):984-1001. [doi:10.1631/jzus.A1400199]

Zhou, J., Goodall, R., Ren, L., et al., 2009. Influences of car body vertical flexibility on ride quality of passenger railway vehicles. Journal of Rail and Rapid Transit, 223(5):461-471. [doi:10.1243/09544097JRRT272]

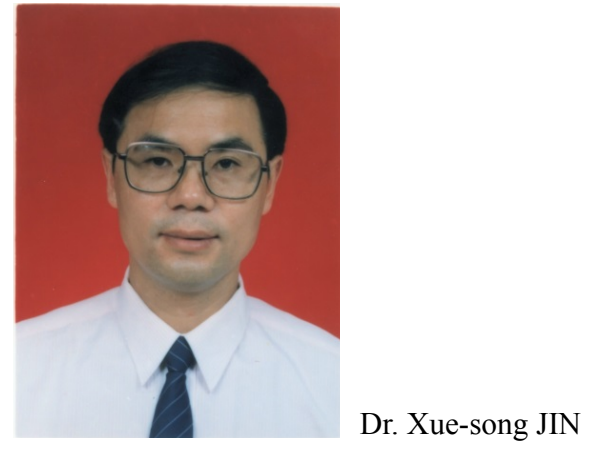

\section{Introducing editorial board member:}

Dr. Xue-song JIN is a new editorial board member of Journal of Zhejiang University-SCIENCE A (Applied Physics \& Engineering) in 2014. Dr. JIN got his Master's degree and $\mathrm{PhD}$ degree in Southwest Jiaotong University, Chengdu, China. Now he works as a professor in the State Key Laboratory of Traction Power, Southwest Jiaotong University. His main research activities include railway vehicle/track dynamics, rolling contact mechanics and wear of wheel/rail systems, and vibration and noise. He has supervised more than 50 important projects on the interaction of wheel/rail systems and the vibration and noise reduction of railways since 2000. So far Dr. JIN has published three books (in Chinese) and more than 200 refereed journal papers.

\section{中文概要:}

\section{本文题目: 高速铁路运营过程中的关键问题: 轮轨磨耗等}

Key problems faced in high-speed train operation

本文概要: 随着高速铁路运营里程和列车运营速度的不断增长, 出现了一些和列车轨道耦合大系统 密切相关的关键科学和技术问题。这些问题不仅影响到列车的运行品质, 甚至威胁到安 全运行, 是当前高速铁路运用和发展中急需解决的问题。本文系统描述了高速铁路在运 营过程中所出现的一些关键科学和技术问题, 并述评了全世界有关这些问题的研究进展、 现状和不足之处, 提出了今后有利于认识和解决这些问题的发展方向。在长期高速运营 的铁路大系统环境中, 这些问题的形成的机理、发生、发展过程和预防措施的研究, 需 要从列车/轨道耦合大系统运营环境 (速度、路况、气候和运用维修)、系统的自身参数 匹配、材料选用和运营成本等全面系统考虑, 并从理论、技术、工艺、监控和维修等方 面解决。

关键词组: 高速铁路; 高速列车; 轮轨磨耗; 列车/轨道耦合动力学; 轮轨滚动接触理论; 减振降噪 理论和技术 